\title{
Parametric Study of Enhanced Condensate Recovery of Gas Condensate Reservoirs using Design of Experiment
}

Nkemakolam Izuwa and Basil C Ogbunude*

Department of Petroleum Engineering, Federal University of Technology, Owerri, Peace Wokoma, University of Port Harcourt, Nigeria

\begin{abstract}
Gas condensate reservoirs usually exhibit reduced well productivity because of condensate dropout that occurs below the dew point pressure. Gas recycling has become one of the most favorable methods of improving recovery of condensed liquid. However, understanding the influence of different injection and reservoir parameters on productivity is of great importance when planning a gas recycling scheme. Traditional methods of sensitization during reservoir simulation for gas condensate fields creates the challenge of quick identification of the most critical properties for sensitization, and hence delay of overall simulation project delivery. This work aims at identifying the key variables that influence productivity of a gas condensate reservoir under a gas recycling scheme using the design of experiment approach (DOE). DOE represents a more effective method for computer-enhanced, systematic approach to experimentation, considering all the factors simultaneously. Identification of these parameters will help simulators achieve best optimization targets and also save time and resources during dynamic simulation projects. Furthermore, it will be shown that experimental design can be used to fit responses (condensate/gas production) to mathematical models that will be able to predict outputs for any given combination of variables.
\end{abstract}

Keywords: Gas condensate; Gas recycling; Design of experiments

\section{Introduction}

Rich gas or retrograde condensate gas reservoir is a common type of hydrocarbon reservoir around the world. Much of the 6,183 trillion cubic feet of worldwide gas reserves can be found in gas condensate reservoirs [1-3]. Hence, gas condensate reservoirs are important to today's energy demand/supply challenges. On the other hand, gas condensate systems have been recognized as the reservoir type with the most complex flow behavior and thermodynamic characteristics [4]. The gas condensate systems exist as a single-phase fluid (gas) at original reservoir conditions, but unlike a wet or dry gas reservoir, it separates into two phases, a gas and a liquid (condensate) at pressures below the saturation pressure of the reservoir [5]. The main problems associated with gas condensate systems are the formation damage effects leading to a reduced relative permeability of gas because of liquid condensate dropout, and permanent loss of valuable liquid due to the trapping capillary effects in the reservoir [6] (Figure 1).

Historically, there are three main methods for gas condensate recovery: natural pressure depletion to the abandonment pressure, full pressure maintenances by gas cycling and partial pressure maintenance

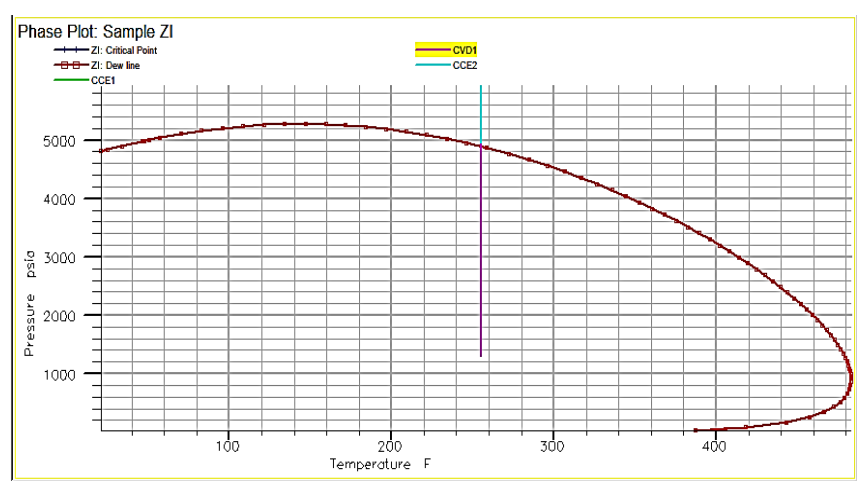

Figure 1: Phase envelope for the gas condensate sample; $\operatorname{Tr}=255^{\circ} \mathrm{F}$, $\mathrm{Pi}=4953 \mathrm{psia}$. by means of gas cycling after previous natural depletion. In order to reduce the impact of the condensate accumulations near the wellbore, gas cycling is usually employed to prevent liquid condensation and to also vaporize dropped out liquid [7]. In properly optimizing recovery from this type of reservoir system, a key question arises to the timing of initiating the gas injection project, as well as understanding the effects of different parameters on the recovery potential of the injection. Though gas-recycling will always improve recovery, there is a need to identify the set of parameters that will lead to a maximum recovery when optimized. Traditional simulation techniques involve testing one factor at a time (OFAT) while holding other factors constant. This work shows how the design of experiments can prove to be a costeffective way to provide information about the interaction of variables and the way the whole reservoir system works while displaying how interconnected factors respond over a wide range of values without requiring direct testing of all possible values. Finally, the design of experiment will be used to develop a system-specific mathematical model that can be used to study the reservoir behaviors based on optimal statistical interactions of the responses (condensate/gas production) and variables (production/reservoir/injection properties).

\section{Methodology}

Generally, injection of gas into the reservoir results in an increase in production [8]. However, to obtain optimum productivity, different production and injection conditions are required to be sensitized.

*Corresponding author: Basil C Ogbunude, Department of Petroleum Engineering, Federal University of Technology, Owerri, Peace Wokoma, University of Port Harcourt, Nigeria, Tel: +2348068628037; E-mail: basilogbunude@yahoo.com

Receive September 02, 2015; Accepted December 12, 2015; Published December 22, 2015

Citation: Izuwa N, Ogbunude BC (2015) Parametric Study of Enhanced Condensate Recovery of Gas Condensate Reservoirs using Design of Experiment. J Pet Environ Biotechnol 7: 259. doi:10.4172/2157-7463.1000259

Copyright: $\odot 2015$ Izuwa N, et al. This is an open-access article distributed under the terms of the Creative Commons Attribution License, which permits unrestricted use, distribution, and reproduction in any medium, provided the original author and source are credited. 
Citation: Izuwa N, Ogbunude BC (2015) Parametric Study of Enhanced Condensate Recovery of Gas Condensate Reservoirs using Design of Experiment. J Pet Environ Biotechnol 7: 259. doi:10.4172/2157-7463.1000259

Such conditions include the injection pressure, injection rate, and the various reservoir and fluid properties. For the purpose of this study, two reservoir models were used create a dynamic simulation model which was used (together with the reservoir, injection and production variables) as input for the design of experiment.

One of the models is the fluid model which was designed using a set of real fluid data obtained from a Niger Delta retrograde gas field. The other model comprises the bulk reservoir, including its petro-physical properties which were hypothetically designed within the confines of Niger Delta reservoir characteristics.

\section{Fluid characterization and generation of compositional PVT tables}

The fluid properties including the phase behavior are greatly dependent on the properties of each component or pseudo-component and composition [9]. The Peng-Robinson (PR) equation of state (EOS) was applied to design the fluid behavioral patterns at different reservoir temperatures and pressures. The results of this design were compared to the laboratory generated results gotten through various routine tests like constant composition expansion (CCE) and constant volume depletion (CVD). Discrepancies in the two models were adjusted by applying heptane-plus characterization techniques and EOS tuning methods. The heavier components (heptane-plus) have various isomers for the same carbon number components and hence they have different characteristics by the presence of different isomers [10]. The heptaneplus characterization involved splitting into three fractions; $\mathrm{C} 7+$, $\mathrm{C} 14+$ and $\mathrm{C} 25+$ before lumping into groups of all pseudo-components according to their molecular weights. The first pseudo-component GRP1 is composed of carbon dioxide only as the only significant nonhydrocarbon. The second pseudo-gas contains nitrogen, methane, and ethane. The amount of nitrogen is not significant; hence, it is assumed that this pseudo-component contains only methane and ethane. The third pseudo-component contains the gasolines; propane, butanes, pentanes, and hexanes. The fourth group is $\mathrm{C} 7$ to $\mathrm{C} 13$, while the fifth is $\mathrm{C} 14$ to $\mathrm{C} 24$. The final group is the heaviest, $\mathrm{C} 25+$ components (Table 1).

The EOS tuning method applied was the 3-Parameter PR model which involved multiple non-linear regression techniques. After several regressions, the fluid was able to be matched. The parameters used to validate the match are shown in Figures 2-6.

\section{Reservoir Model and Experimental Design}

A simple five-spot model was designed using hypothetical grid blocks, rock properties and initialization properties. The synthetic model has Cartesian coordinates with block-centered geometry having length of $328 \mathrm{ft}$. in the $\mathrm{X}$ and $\mathrm{Y}$ directions having 10x10x7 grids. The reservoir which was at a depth of $9560 \mathrm{ft}$. below seas level has an initial reservoir pressure of 4953 psia (Figure 7).

Sensitivity analyses are common during reservoir simulations. To understand the prevailing factors that are most contributory to the final

\begin{tabular}{|c|c|c|}
\hline Components & Mol \% & Weight fraction, $\%$ \\
\hline GRP1 & 3.35 & 6.7572 \\
\hline GRP2 & 90.69 & 70.112 \\
\hline GRP3 & 3.69 & 9.1893 \\
\hline GRP4 & 1.9992 & 11.142 \\
\hline GRP5 & 0.26079 & 2.6309 \\
\hline GRP6 & 0.010017 & 0.16876 \\
\hline \multicolumn{2}{r}{ Table 1: Composition of pseudo-components. } \\
\hline
\end{tabular}

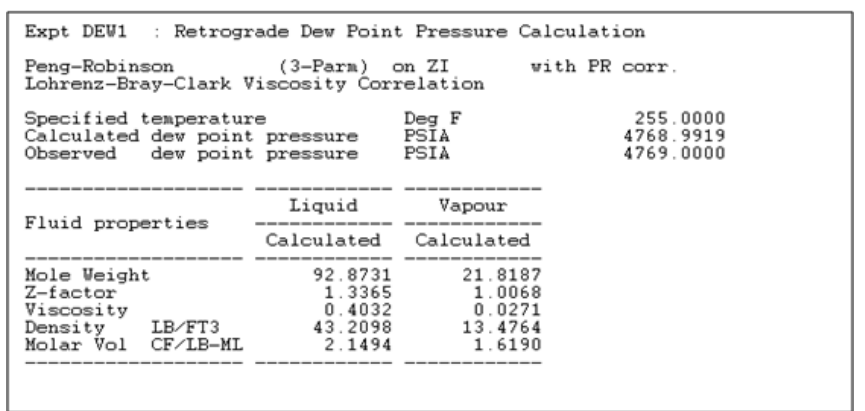

Figure 2: Result of saturation pressure EOS tuning showing the matched dew point pressure.

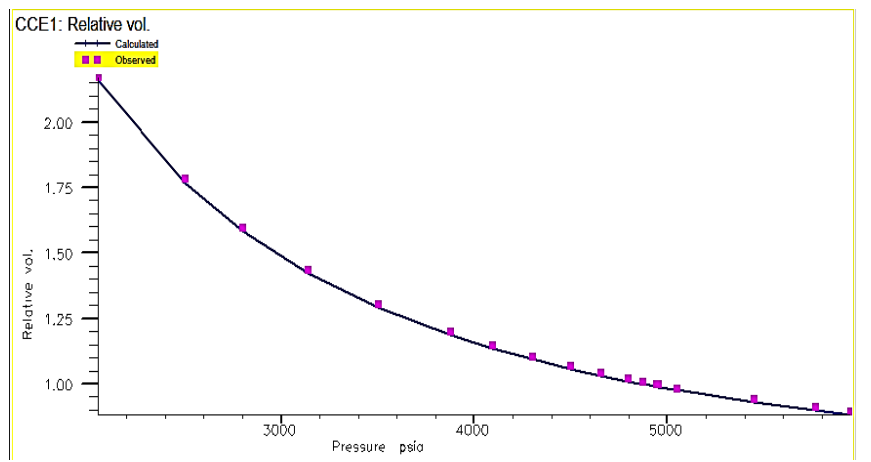

Figure 3: Experimental and calculated relative volume for CCE@ $255^{\circ} \mathrm{F}$.

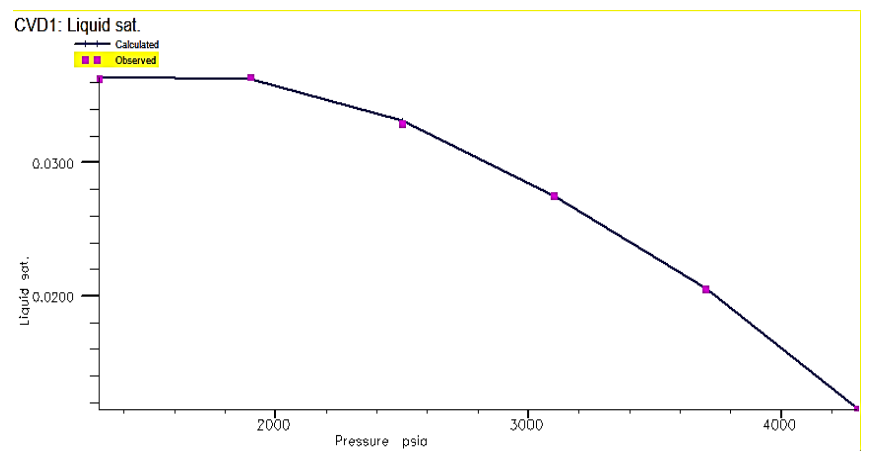

Figure 4: Experimental and calculated liquid saturation for CVD@225F.

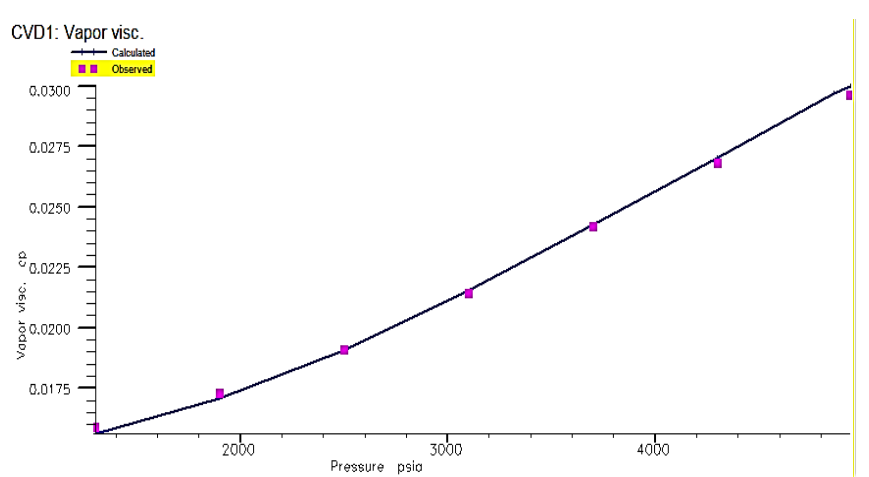

Figure 5: Experimental and calculated gas viscosity for CVD @ $255^{\circ} \mathrm{F}$. 
Citation: Izuwa N, Ogbunude BC (2015) Parametric Study of Enhanced Condensate Recovery of Gas Condensate Reservoirs using Design of Experiment. J Pet Environ Biotechnol 7: 259. doi:10.4172/2157-7463.1000259

Page 3 of 8

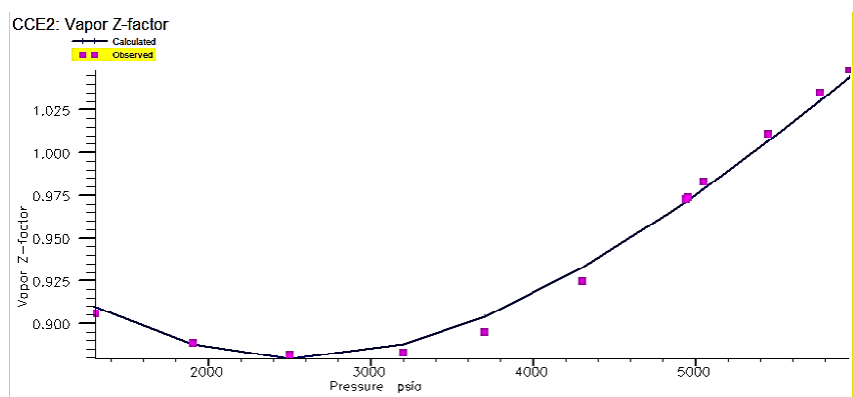

Figure 6: Experimental and calculated gas compressibility factor data for CVD @255F.

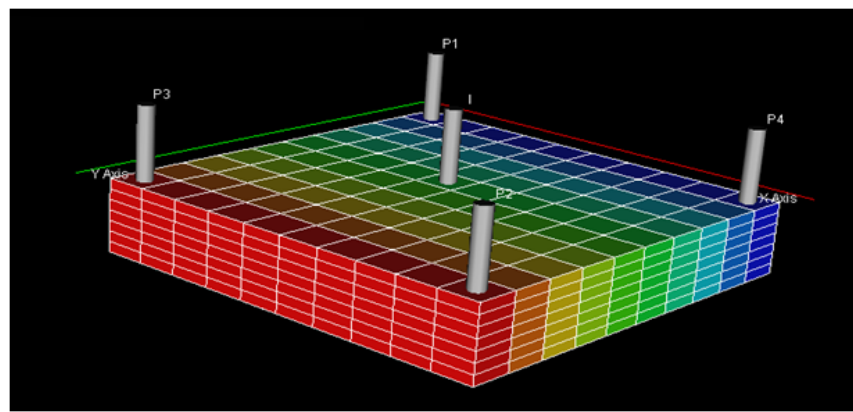

Figure 7: 3D simulation model of reservoir.

\begin{tabular}{|c|c|c|c|c|}
\hline Factor & Name & Unit & Low & High \\
\hline A & PORO & fraction & 0.1 & 0.38 \\
\hline B & PERM & mD & 100 & 1000 \\
\hline C & NTG & fraction & 0.4 & 0.9 \\
\hline D & Kv/Kh & fraction & 0.01 & 0.1 \\
\hline E & Scc & fraction & 0.1 & 0.4 \\
\hline F & CGR & stb/scf & 50 & 240 \\
\hline G & Qinj & scf/day & 2480 & 24800 \\
\hline H & Pinj & psia & 1400 & 7000 \\
\hline J & H & ft. & 40 & 200 \\
\hline K & Pr & psia & 3000 & 7000 \\
\hline L & Krg & fraction & 0.2 & 0.85 \\
\hline
\end{tabular}

Table 2: Plackett-Burman Design showing the factors and levels (Low and High). responses in the dynamic modeling of a gas recycling project in a gas condensate reservoir, the DOE technique was applied. In this method, eleven properties expected to influence gas and condensate production are taken as factors to be used in the experimental design procedure and thus determine the statistical effects of these different parameters on gas and condensate recovery. Responses are the condensate and gas production, generated for each combination of parameters. DOE provides information about the interactions of the factors and responses and how interconnected factors respond over a wide range of values, without the need to test all possible values directly. The Plackett-Burman DOE Design for selection of significant parameters was used for the eleven factors (parameters), where each factor was varied over two levels (low and high) based on regional petrophysical and operational characteristics (Table 2).

This generates a set of saturated screening designs based on Plackett-Burman structures, the number of factors being one less than the number of required runs. These runs are a mixture of the different levels of the factors as shown in Table 3.

\section{Results}

With the results of the design, the various levels of significance of the eleven parameters on gas and condensate production responses were observed using the normal probability plot, the half-normal probability plot and the Pareto chart. Interpretation of the charts gave rise to identification of seven factors that showed the most significant impact on the production responses.

These parameters are

- Porosity

- $\quad$ Net-to-Gross ratio

- $\mathrm{Kv} / \mathrm{Kh}$

- Injection Rate

- Injection Pressure

- Thickness

- Reservoir Pressure

\section{Development of proxy}

As an extension to the work, a mathematical model was developed using D-optimal Response Surface Method (RSM) to study the effects

\begin{tabular}{|c|c|c|c|c|c|c|c|c|c|c|c|c|c|}
\hline & Factor 1 & Factor 2 & Factor 3 & Factor 4 & Factor 5 & Factor 6 & Factor 7 & Factor 8 & Factor 9 & Factor 10 & Factor 11 & Response 1 & Response 2 \\
\hline Run & A:PORO & B:PERM & C:NTG & $\mathrm{D}: \mathrm{Kv} / \mathrm{Kh}$ & $\mathrm{E}: S c c$ & $F: C G R$ & G:Qinj & H:Pinj & $\mathrm{J}: \mathrm{H}$ & $\mathrm{K}: \mathrm{Pr}$ & $\mathrm{L}: \mathrm{Krg}$ & Gas Prod & Cond Prod \\
\hline & fraction & $\mathrm{mD}$ & fraction & fraction & fraction & stb/scf & scf/day & psia & $\mathrm{ft}$. & psia & fraction & Mscf & bbls \\
\hline 1 & 0.38 & 100 & 0.9 & 0.1 & 0.1 & 240 & 24800 & 7000 & 40 & 3000 & 0.2 & $1.36 \mathrm{E}+08$ & 1113184 \\
\hline 2 & 0.1 & 1000 & 0.4 & 0.1 & 0.4 & 50 & 24800 & 7000 & 200 & 3000 & 0.2 & $1.36 \mathrm{E}+08$ & 747511.7 \\
\hline 3 & 0.1 & 100 & 0.4 & 0.01 & 0.1 & 50 & 2480 & 1400 & 40 & 3000 & 0.2 & 2242553 & 51224.29 \\
\hline 4 & 0.38 & 100 & 0.9 & 0.1 & 0.4 & 50 & 2480 & 1400 & 200 & 3000 & 0.85 & 95895064 & 2225146 \\
\hline 5 & 0.1 & 100 & 0.9 & 0.01 & 0.4 & 240 & 2480 & 7000 & 200 & 7000 & 0.2 & 52022840 & 1503648 \\
\hline 6 & 0.38 & 1000 & 0.9 & 0.01 & 0.1 & 50 & 24800 & 1400 & 200 & 7000 & 0.2 & $1.36 \mathrm{E}+08$ & 4400179 \\
\hline 7 & 0.1 & 1000 & 0.9 & 0.01 & 0.4 & 240 & 24800 & 1400 & 40 & 3000 & 0.85 & $1.36 \mathrm{E}+08$ & 212694.7 \\
\hline 8 & 0.1 & 1000 & 0.9 & 0.1 & 0.1 & 50 & 2480 & 7000 & 40 & 7000 & 0.85 & 9727697 & 276220.8 \\
\hline 9 & 0.38 & 1000 & 0.4 & 0.1 & 0.4 & 240 & 2480 & 1400 & 40 & 7000 & 0.2 & 15023919 & 425837.5 \\
\hline 10 & 0.38 & 100 & 0.4 & 0.01 & 0.4 & 50 & 24800 & 7000 & 40 & 7000 & 0.85 & $1.36 \mathrm{E}+08$ & 1034213 \\
\hline 11 & 0.1 & 100 & 0.4 & 0.1 & 0.1 & 240 & 24800 & 1400 & 200 & 7000 & 0.85 & 85265984 & 196071.7 \\
\hline 12 & 0.38 & 1000 & 0.4 & 0.01 & 0.1 & 240 & 2480 & 7000 & 200 & 3000 & 0.85 & 4651961 & 101806.9 \\
\hline
\end{tabular}

Table 3: Experimental Design Table showing the factors and responses used for the design. 
Citation: Izuwa N, Ogbunude BC (2015) Parametric Study of Enhanced Condensate Recovery of Gas Condensate Reservoirs using Design of Experiment. J Pet Environ Biotechnol 7: 259. doi:10.4172/2157-7463.1000259

Page 4 of 8

of these factors on gas and condensate recovery. RSM designs help to quantify the relationships between one or more measured responses and the vital input factors or parameters. The D-optimal criteria is one of the optimalities that selects design points in a way that minimizes the variance associated with the estimates of specified model coefficients. The aim is to generate a model that represents the responses using quadratic interactions of the factors. Using the quadratic model, an overall candidate point set was created, after which fifty -five specific design points (the experimental runs that would be done) were chosen after which the proxy was generated.

This proxy was tested using statistical indicators to ascertain its degree of error as shown in Tables 4 and 5 for gas and condensate production respectively.

At the end of the experimental design, the following equations were generated for the gas and condensate production;

$$
\begin{aligned}
& \boldsymbol{G}_{p}, C_{p}=A_{1}+A_{2}(\varnothing)+A_{3}(N T G)+A_{4}\left(K_{V} / K_{H}\right)+A_{5}\left(Q_{i j j}\right)+A_{6}(H)+A_{7}\left(P_{r}\right)+A_{8}\left(P_{i v j}\right) \\
& +A_{9}(\varnothing * N T G)+A_{10}\left(\varnothing * K_{V} / K_{H}\right)+A_{11}\left(\varnothing * Q_{\text {inj }}\right)+A_{12}(\varnothing * H)+A_{13}\left(\varnothing * P_{r}\right) \\
& +A_{14}\left(\varnothing * P_{i j i}\right)+A_{15}\left(N T G^{*} K_{V} / K_{H}\right)+A_{16}\left(N T G^{*} Q_{i v i}\right)+A_{17}\left(N T G^{*} H\right)+A_{18}\left(N T G^{*} P_{r}\right) \\
& +A_{19}\left(N T G * P_{i j i}\right)+A_{20}\left(K_{V} / K_{H}{ }^{*} Q_{i n j}\right)+A_{21}\left(K_{V} / K_{H}{ }^{*} H\right)+A_{22}\left(K_{V} / K_{H}{ }^{*} P_{r}\right)+A_{23}\left(K_{V} / K_{H}{ }^{*} P_{i j j}\right) \\
& +A_{24}\left(Q_{i j j} * H\right)+A_{25}\left(Q_{i j j} * P_{r}\right)+A_{26}\left(Q_{i j j} * P_{i j j}\right)+A_{27}\left(H * P_{r}\right)+A_{28}\left(H * P_{i j i}\right)+A_{29}\left(P_{r} * P_{i v j}\right) \\
& +A_{3029}\left(\varnothing^{2}\right)+A_{31}\left(N T G^{2}\right)+A_{32}\left[\left(K_{V} / K_{H}\right)^{2}\right]+A_{33}\left(Q_{i j j}{ }^{2}\right)+A_{34}\left(H^{2}\right)+A_{35}\left(P_{r}^{2}\right)+A_{36}\left(P_{i n j}{ }^{2}\right)
\end{aligned}
$$

The values of the coefficients for gas and condensate equations are represented in Table 6 .

The mathematical model was validated by comparing them to results generated from an independent dynamic simulator. For the gas production model, the relative error when compared to simulation results was found to be $3.8 \%$, while that for condensate production prediction model was $3.6 \%$.

Finally, a sensitivity analysis was carried out on these parameters using the mathematical models to help understand how these factors influence production in a gas condensate reservoir.

\section{Effects of injection rate and pressure on gas and condensate production}

Five injection rates were chosen for the injection process ranging from 19,800 Mscf/day to 5,900 Mscf/day, and the effects of each rate on gas and condensate production was analyzed.

It can be seen from the graphs above that the maximum gas production occurs at the maximum injection rate. This also coincides

\begin{tabular}{|c|c|c|}
\hline \multirow[t]{2}{*}{ Constants } & \multicolumn{2}{|c|}{ Coefficients } \\
\hline & Gas Production & Condensate Production \\
\hline $\mathrm{A}_{1}$ & $4.60738^{*} 10^{7}$ & $1.04572 * 10^{6}$ \\
\hline $\mathrm{A}_{2}$ & $-5.30696^{*} 10^{7}$ & $-4.41239 * 10^{6}$ \\
\hline $\mathrm{A}_{3}$ & $-1.35533 * 10^{8}$ & $-3.74945^{*} 10^{6}$ \\
\hline $\mathrm{A}_{4}$ & $-7.34830^{*} 10^{7}$ & $2.43062 * 10^{6}$ \\
\hline $\mathrm{A}_{5}$ & 1176.33385 & 51.19948 \\
\hline $\mathrm{A}_{6}$ & $4.49593 * 10^{5}$ & -4815.17296 \\
\hline $\mathrm{A}_{7}$ & -7244.68379 & -15.93230 \\
\hline $\mathrm{A}_{8}$ & -9111.02877 & -25.52929 \\
\hline $\mathrm{A}_{9}$ & $1.56111 * 10^{8}$ & $4.7435^{*} 10^{6}$ \\
\hline $\mathrm{A}_{10}$ & $5.30660 * 10^{8}$ & $1.5562 * 10^{6}$ \\
\hline $\mathrm{A}_{11}$ & -6257.17754 & 11.78361 \\
\hline $\mathrm{A}_{12}$ & $7.33963 * 10^{5}$ & 33198.09102 \\
\hline $\mathrm{A}_{13}$ & -2228.53231 & 630.74498 \\
\hline $\mathrm{A}_{14}$ & 13414.38501 & 12.50100 \\
\hline $\mathrm{A}_{15}$ & $-2.22378^{\star} 10^{8}$ & $-3.20724^{*} 10^{6}$ \\
\hline $\mathrm{A}_{16}$ & -2319.93384 & -7.00348 \\
\hline $\mathrm{A}_{17}$ & $3.29370 * 10^{5}$ & 10852.73623 \\
\hline $\mathrm{A}_{18}$ & 4522.62490 & 143.36173 \\
\hline $\mathrm{A}_{19}$ & -208.50250 & -22.02281 \\
\hline $\mathrm{A}_{20}$ & 5071.25296 & 40.98690 \\
\hline $\mathrm{A}_{21}$ & -78705.33842 & 3950.85908 \\
\hline $\mathrm{A}_{22}$ & 7658.12602 & -72.92741 \\
\hline $\mathrm{A}_{23}$ & 33312.15701 & 335.85908 \\
\hline $\mathrm{A}_{24}$ & -14.36637 & 0.048639 \\
\hline $\mathrm{A}_{25}$ & -0.25318 & $-2.87403^{*} 10^{-3}$ \\
\hline $\mathrm{A}_{26}$ & $3.33435^{\star} 10^{-3}$ & 0.000000 \\
\hline $\mathrm{A}_{27}$ & 42.58720 & 1.43811 \\
\hline $\mathrm{A}_{28}$ & 29.45186 & 0.074765 \\
\hline $\mathrm{A}_{29}$ & 1.22107 & $7.49886^{*} 10^{-3}$ \\
\hline $\mathrm{A}_{30}$ & $8.03938^{*} 10^{6}$ & $-3.59965^{\star} 10^{6}$ \\
\hline $\mathrm{A}_{31}$ & $7.70745^{\star} 10^{7}$ & $1.84886^{*} 10^{6}$ \\
\hline $\mathrm{A}_{32}$ & $7.13256^{*} 10^{8}$ & $-1.52469^{*} 10^{7}$ \\
\hline $\mathrm{A}_{33}$ & 0.31962 & $-7.03805^{\star} 10^{-4}$ \\
\hline $\mathrm{A}_{34}$ & -3031.83758 & -35.35163 \\
\hline $\mathrm{A}_{35}$ & 0.13735 & -0.017308 \\
\hline $\mathrm{A}_{36}$ & -0.80404 & $-1.94740^{*} 10^{-3}$ \\
\hline
\end{tabular}
with the maximum injection pressure. However, the lowest injection

\begin{tabular}{|c|c|c|c|}
\hline Indicator & Value & Indicator & Value \\
\hline Std. Dev. & - & R-Squared & 0.987586 \\
\hline Mean & 81063030 & Adj R-Squared & 0.964719 \\
\hline C.V. $\%$ & 12.75986 & Pred R-Squared & 0.822069 \\
\hline PRESS & $2.91 \mathrm{E}+16$ & Adeq Precision & 20.91767 \\
\hline
\end{tabular}

Table 4: Statistical summary for gas prediction model.

\begin{tabular}{|c|c|c|c|}
\hline Indicator & Value & Indicator & Value \\
\hline Std. Dev. & - & R-Squared & 0.994997 \\
\hline Mean & 1352464 & Adj R-Squared & 0.98578 \\
\hline C.V. $\%$ & 10.06817 & Pred R-Squared & 0.934002 \\
\hline PRESS & $4.65 E+12$ & Adeq Precision & 40.23579 \\
\hline
\end{tabular}

Table 5: Statistical summary for condensate prediction model.
Table 6: Coefficients of gas and condensate equation.

rate, 5,900 Mscf/day does not give the lowest cumulative gas production. Generally, the optimum injection rate will always depend 
Citation: Izuwa N, Ogbunude BC (2015) Parametric Study of Enhanced Condensate Recovery of Gas Condensate Reservoirs using Design of Experiment. J Pet Environ Biotechnol 7: 259. doi:10.4172/2157-7463.1000259

on the prevailing economic conditions of the operating environment (Figures 8-11).

\section{Effects of permeability ratio on gas and condensate production}

For this parameter, the sensitivity was done at different injection rates. This was aimed at studying the possible existing of interaction between the two parameters for both gas and condensate production and to confirm if the little changes in condensate production observed with increasing injection pressure observed in Figure 12 was particular to injection rates only.

The permeability ratio does not have a lot of variation on gas production, especially at very low injection rate. However, the effect of permeability ratio on condensate production is very pronounced when correlated with injection pressure, as seen in Figures 13. At very high

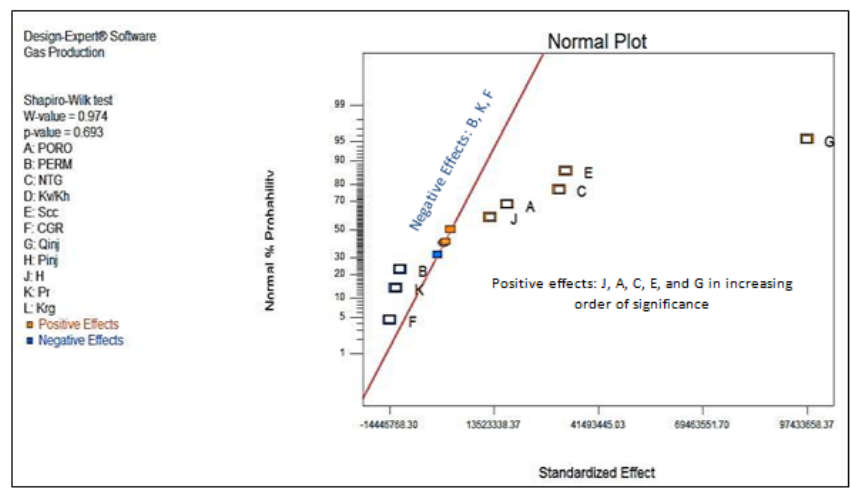

Figure 8: Graph of Normal \% Probability vs. Standardized Effects for Gas Production.
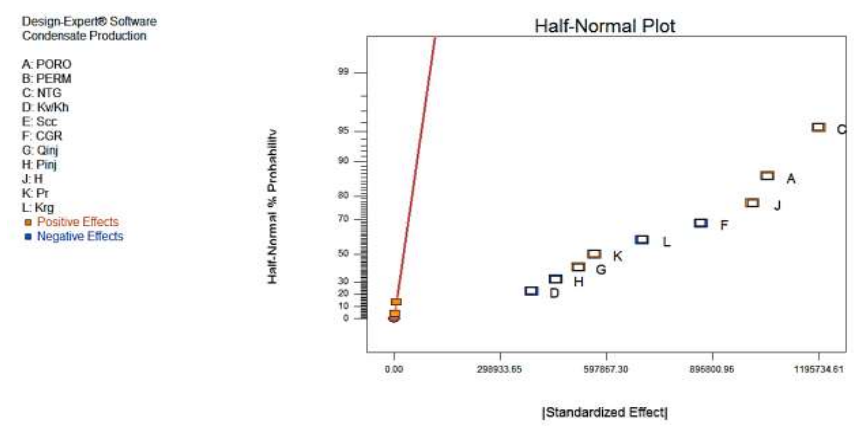

Figure 9: Half-Normal \% Probability vs. Absolute Standardized Effects for Cond. Production.

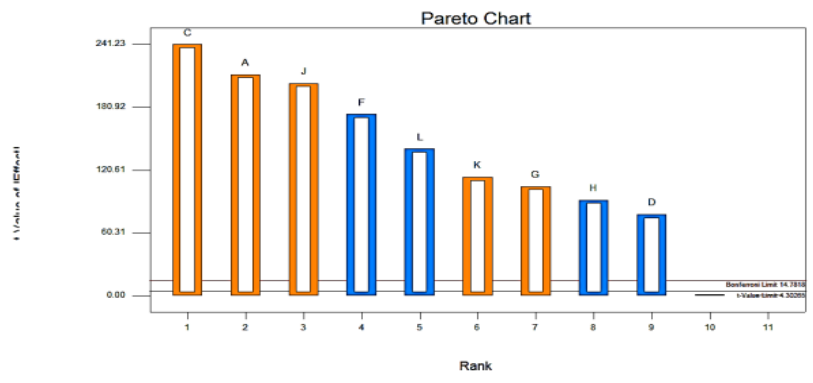

Figure 10: Pareto Chart for Cond Prod., showing factor Casthemost significant parameter.

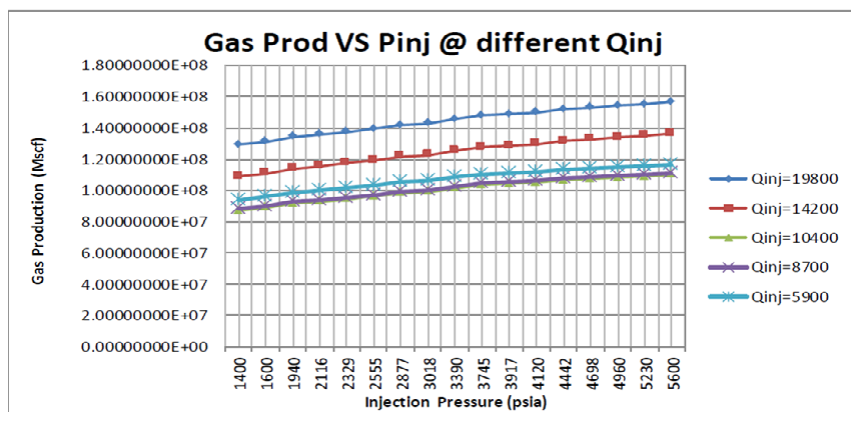

Figure 11: Effects of injection rate and pressure on gas production.

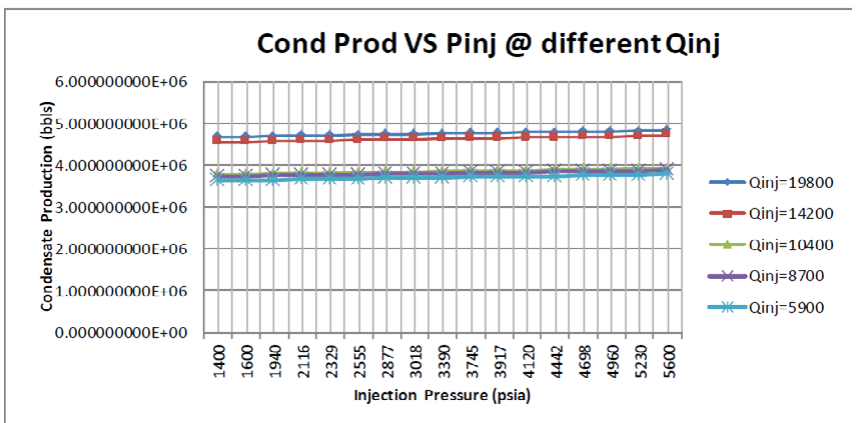

Figure 12: Effects of injection rate and pressure on condensate production.

injection rates and injection pressures, the highest permeability ratio $(\mathrm{Kv} / \mathrm{Kh}=0.1)$ gives the maximum condensate production while at very low injection rates and injection pressures.

\section{Effects of net-to-gross ratio on gas and condensate production}

Both gas and condensate production showed similar effects with NTG sensitivity (Figures 14 and 15). As expected, higher values of NTG gave lower responses of productivity.

\section{Effects of porosity on gas and condensate production}

For this sensitivity, the porosity was correlated with different injection rates to study their effects on gas and condensate production (Figures 16 and 17). As expected, the least production occurs in the least porous system. However, the least gas production for each given porosity system does not coincide with the lowest injection rate. A similar observation was also made when studying the effects of injection rate at different injection pressures (Figure 11). Again, this shows that economic conditions could influence the nature of the outcome of the sensitivity involving injection rates. Similar observations were made in the condensate analysis.

Effects of gross thickness on gas and condensate production at varying porosity

Using an NTG of 0.96, the thickness was sensitized on at different porosity. At high porosity, it is observes that the maximum production coincides with the highest thickness. However, as the porosity decreases, this fails to hold. At the lowest porosity system of 0.11 , it is observed that the highest gas production does not coincide with the highest thickness of $200 \mathrm{ft}$. All the above hold true for the condensate 
Citation: Izuwa N, Ogbunude BC (2015) Parametric Study of Enhanced Condensate Recovery of Gas Condensate Reservoirs using Design of Experiment. J Pet Environ Biotechnol 7: 259. doi:10.4172/2157-7463.1000259
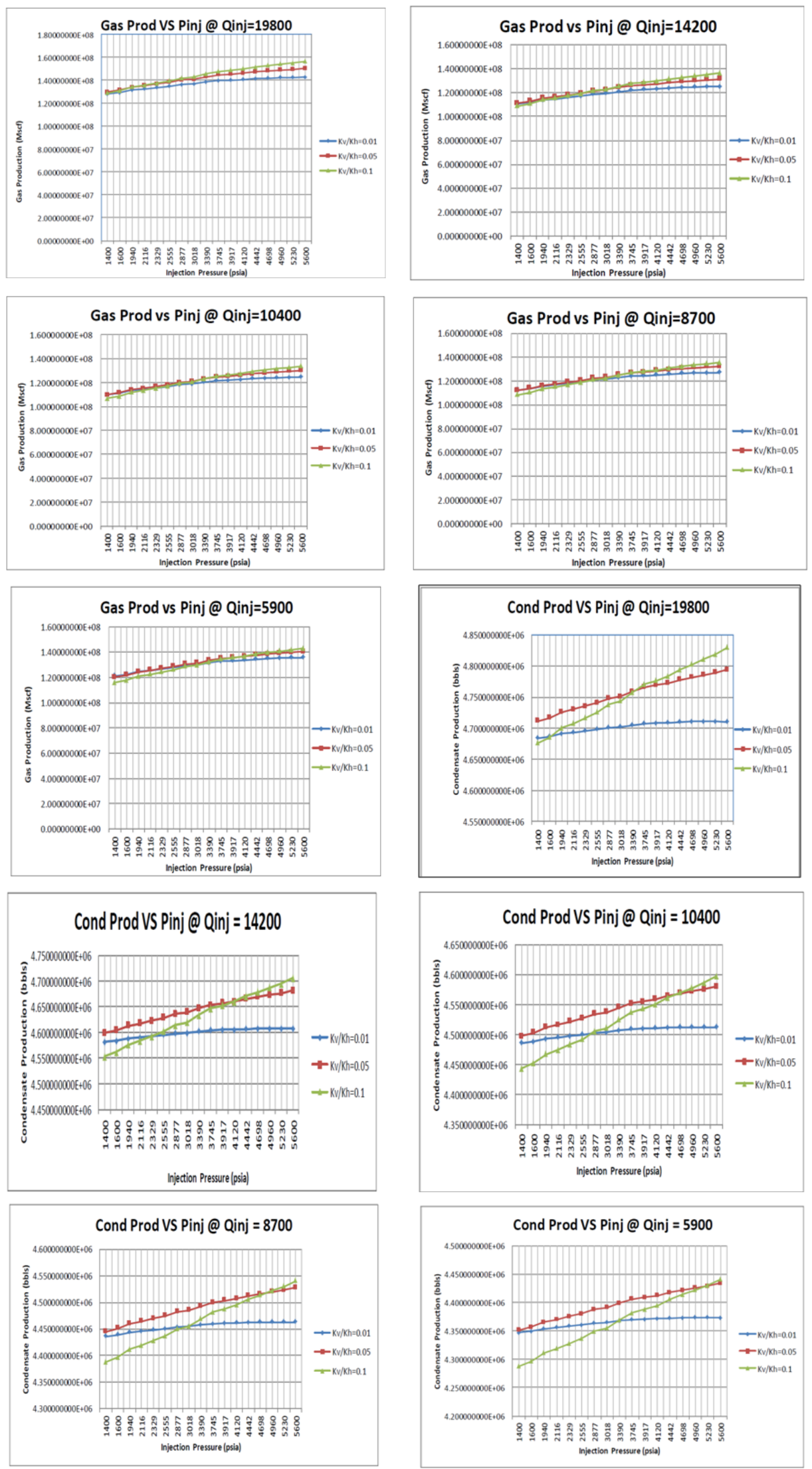

Figures 13: Effects of different permeability ratios on gas and cond. production at different injection rates. 
Citation: Izuwa N, Ogbunude BC (2015) Parametric Study of Enhanced Condensate Recovery of Gas Condensate Reservoirs using Design of Experiment. J Pet Environ Biotechnol 7: 259. doi:10.4172/2157-7463.1000259

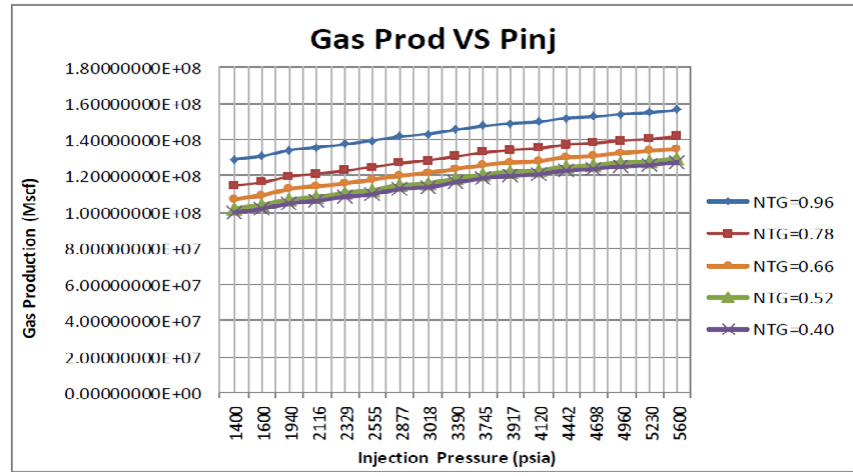

Figure 14: Effects of Net-to-Gross ration gas production.

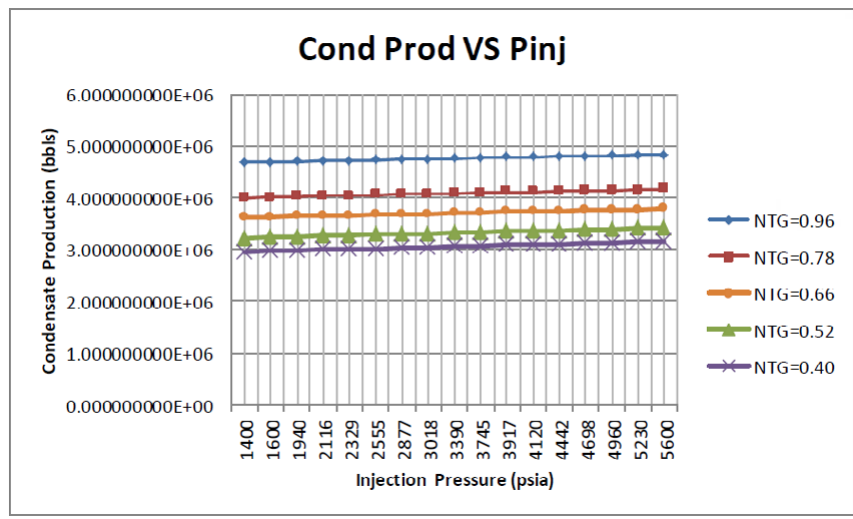

Figure 15: Effects of Net-to-Gross ration condensate production.

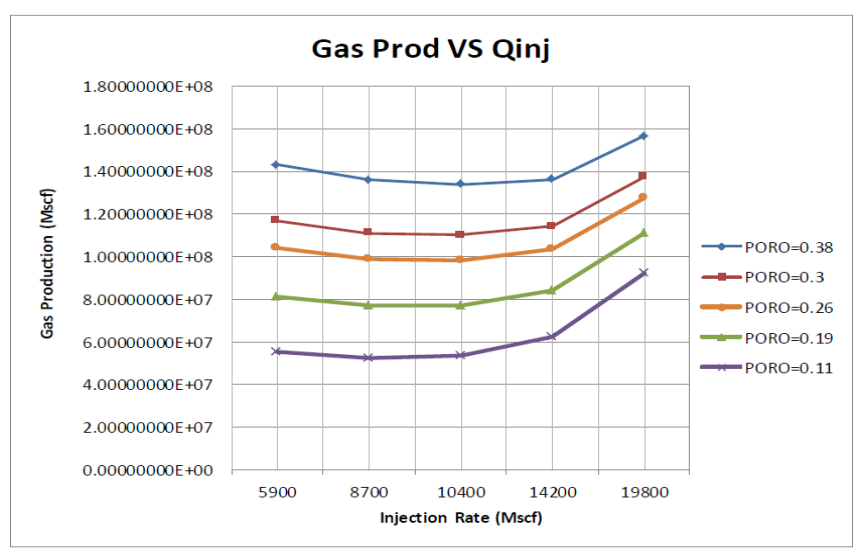

Figure 16: Effects of porosity on gas production at varying injection rates.

production, except that even at low porosity systems, the maximum production still coincides with the maximum thickness of $200 \mathrm{ft}$ (Figures 18 and 19).

\section{Conclusion}

Gas condensate reservoirs are known to be very valuable because of the condensate's high API value. Producing this fluid however has been met with several challenges over the years. This is abated by injection of produced gas into the formation to evaporate the condensed fluid.

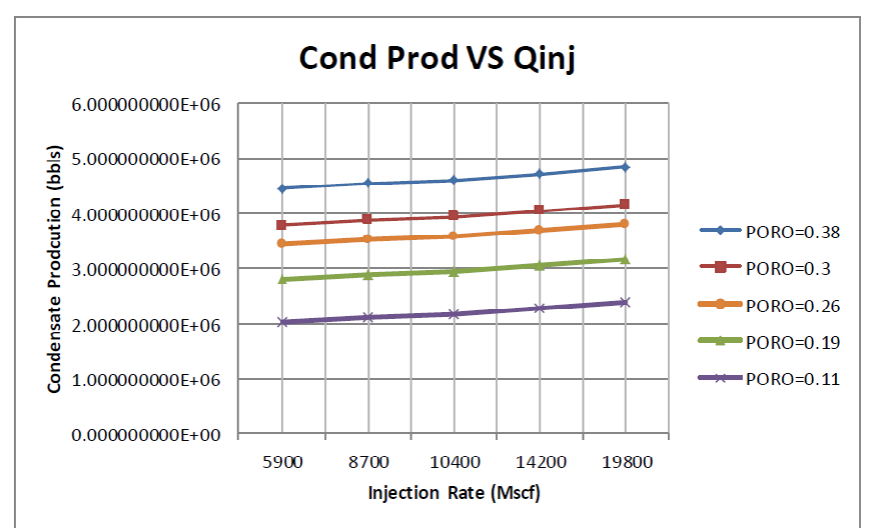

Figure 17: Effects of porosity on condensate production at varying injection rates.

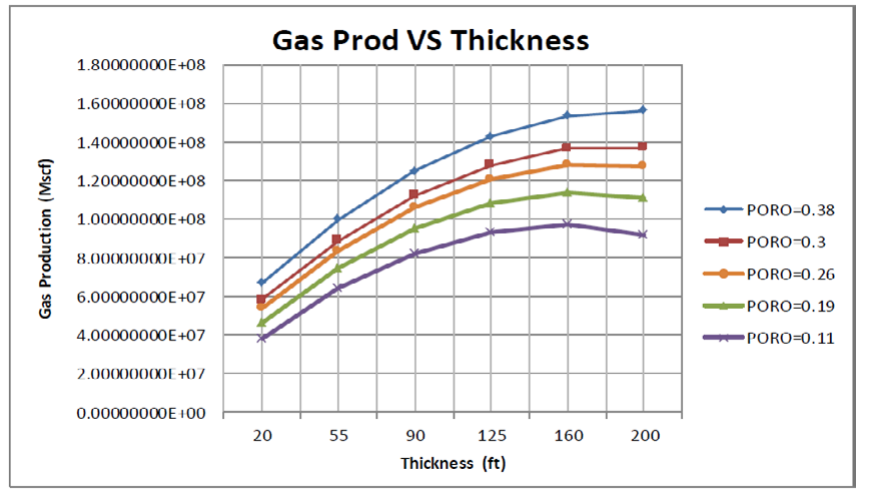

Figure 18: Effects of thickness on gas production at varying porosity values.

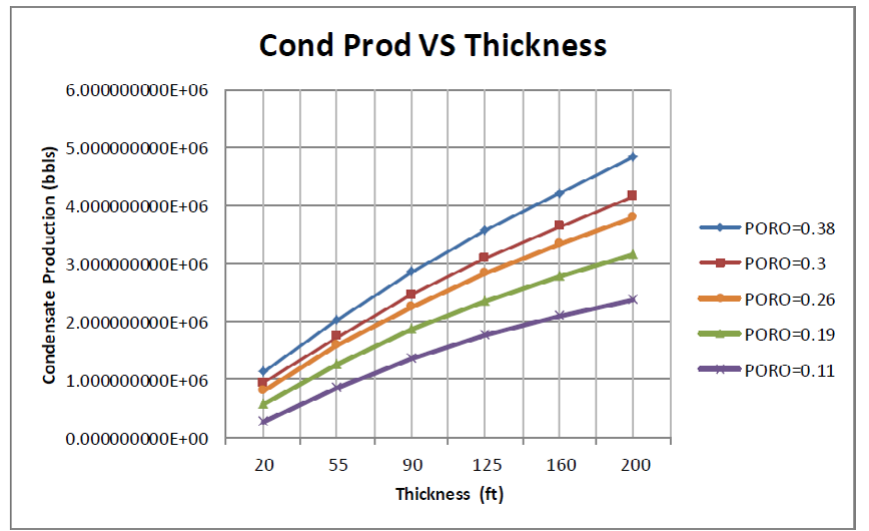

Figure 19: Effects of thickness on condensate production at varying porosity values.

Due to the sensitive nature of this kind of reservoir, it is very important to understand the parameters that influence production, and know how these parameters influence production. This work proposed a hypothetical model that was used to study the effects of different parameters on gas and condensate production through statistical optimization. It was discovered that several parameters did affect production of reservoir fluids under varying conditions more than others. 
Citation: Izuwa N, Ogbunude BC (2015) Parametric Study of Enhanced Condensate Recovery of Gas Condensate Reservoirs using Design of Experiment. J Pet Environ Biotechnol 7: 259. doi:10.4172/2157-7463.1000259

Page 8 of 8

\section{References}

1. Ahmed T, Evans J, Kwan R, Vivian T (1998) "Wellbore liquid blockage in gas condensate reservoirs". Paper SPE 51050, Presented at the 1998 SPE Eastern Regional meeting, Pittsburgh.

2. Anderson M (1997) "Design of Experiments", The Industrial Physicist, American Institute of Physics.

3. Nathan M, Hadi N, Ding Z (2010) "Application of Horizontal Wells to Reduce Condensate Blockage in Gas Condensate Reservoirs". Paper SPE 130996 presented at CPS/SPE International Oil and Gas Conference and Exhibition, Beijing, China

4. Chunmei S (2009) "Flow Behavior of Gas Condensate Wells". A Dissertation Submitted to the Department of Energy Resources Engineering, Stanford University, California, USA

5. Fevang O, Whitson CH (1996) "Modeling Gas Condensate Well Deliverability". Paper SPE 30714 presented at the SPE Annual Technical conference and Exhibition, Dallas.
6. Barnum RS, Brinkman FP, Richardson TW, Spillette AG (1995) "Gas Condensate Reservoir Behavior: Productivity and Recovery Reduction due to Condensation". Dallas, Texas, USA.

7. Kenyon DE, Behie GA (1987) "Third SPE Comparative Solution Project: Gas Cycling of Retrograde Condensate Reservoirs". Paper SPE 122 Chunmei 78, Journal of Petroleum Technology.

8. Bourbiaux B (1994) "Parametric study of Gas condensate Reservoir Behavior during Depletion: A Guide for Development planning", Paper SPE 28848 , presented at the 1994 EUROPEC, London, UK.

9. Henderson GD, Danesh A, Trehran DH, Peden JM (1993) "An Investigation Governing the Flow and Recovery in Different Flow Regimes Present in Gas Condensate Reservoirs", Paper SPE 26661, presented at the 1993 Annual Technical Conference and Exhibition, Houston, Texas.

10. Whitson CH, Torp SB (1983) "Evaluating constant-volume depletion data". J Pet Tech 35: 610-20 